2. Luks A, Robertson H, Swenson ER. An ultracyclist with pulmonary edema during the bicycle race across America. Med Sci Sports Exerc. In press.

3. Ginsberg JS, Wells PS, Kearon C, et al. Sensitivity and specificity of a rapid whole-blood assay for D-dimer in the diagnosis of pulmonary embolism. Ann Intern Med. 1998; 129(12):1006-1011.

4. Schreijer AJ, Cannegieter SC, Meijers JC, Middeldorp S, Buller HR, Rosendaal FR. Activation of coagulation system during air travel: a crossover study. Lancet. 2006; 367(9513):832-838.

5. De Monye W, Sanson BJ, Mac Gillavry MR, et al. Embolus location affects the sensitivity of a rapid quantitative D-dimer assay in the diagnosis of pulmonary embolism. Am J Respir Crit Care Med. 2002;165(3):345-348.

\section{Reply to High-Altitude Pulmonary Edema Getting Worse After Descent? An Unlikely Event}

\section{To the Editor:}

We appreciate the comments of Luks and Swenson but disagree with their alternative explanations.

With regard to their question of underlying pulmonary hypertension as the cause of respiratory distress, our patient had only trace tricuspid regurgitant jet, and, therefore, no estimation of the pulmonary artery systolic pressure could be made. Although it is true that underlying pulmonary hypertension may lead to a propensity for hypoxia and dyspnea, the patient had no known risk factors for pulmonary hypertension nor other echo findings that would have suggested a cardiac etiology (eg, atrial septal defect) or indirect evidence (eg, right ventricular dilation or dysfunction) of pulmonary hypertension in an otherwise healthy young male.

In terms of the risk for pulmonary embolus, we disagree that the patient had more than a low clinical probability of having a pulmonary embolus. He had a score of 1.5 using the widely accepted Wells clinical decision rule $^{1}$ (heart rate $>100 \mathrm{bpm}$ ), which suggests a low risk of having a pulmonary embolism. In this setting of a low clinical probability along with a negative D-dimer, there is up to a $99.6 \%$ negative predictive value in ruling out a pulmonary embolism in patients presenting to the emergency department, ${ }^{2}$ thus making further imaging unnecessary.

Furthermore, it is unclear if the results of the article involving coagulation factors after air travel ${ }^{3}$ are applicable to high-altitude mountaineering. That study describes subjects who are immobile for 8 hours while in flight. Although both mountaineering and air travel involve hypobaric hypoxia, mountaineering involves vigorous activity, which has an unknown effect on the levels of coagulation factors.
Finally, the patient's clinical presentation and course is truly inconsistent with a diagnosis of pulmonary embolus. A pulmonary embolus significant enough to present with severe hypoxia and diffuse pulmonary infiltrates would not likely be subsegmental or resolve completely over 24 hours.

We believe our patient's clinical diagnosis was most consistent with a late presentation of high-altitude pulmonary edema.

Jared Strote, MD, FACEP Jordan Prutkin, MD

University of Washington Seattle, WA, USA

\section{References}

1. Wells PS, Anderson DR, Rodger M, et al. Derivation of a simple clinical model to categorize patients' probability of pulmonary embolism: increasing the model's utility with the SimpliRED D-dimer. Thomb Haemost. 2000;83:416420.

2. Dunn KL, Wolf JP, Dorfman DM, Fitzpatrick P, Baker JL, Goldhaber SZ. Normal D-dimer levels in emergency department patients suspected of acute pulmonary embolism. J Am Coll Cardiol. 2002;40:1475-1478.

3. Schreijjer AJM, Cannegieter SC, Meijers JCM, Middeldorp S, Büller HR, Rosendaal FR. Activation of coagulation system during air travel: a crossover study. Lancet. 2006;367: 832-838.

\section{Prevention of Acute Mountain Sickness in Nepali Porters: A Controlled Trial}

\section{To the Editor:}

We were delighted to read one of the few research articles on Nepali porters in the Mount Everest region. ${ }^{1}$ Being from this region, we were particularly interested in reviewing the article meticulously, learning from its findings, and applying the information to our medical practice. While studying the article, we came across some points that we hope the authors will clarify.

The first question relates to the methods and the exclusion criteria for enrollment into the study, which were acute mountain sickness (AMS), diabetes mellitus, glaucoma, epilepsy, or sulphonamide allergy. How were these conditions considered? From history, any medical documentation, drugs the porters had taken, or investigations done at the research site? It appears to us that most Nepalese do not know about these conditions.

The second point is the incidence of AMS found: 